I am indebted to Mr. J. E. H. Roberts, whose exceptional knowledge on these matters is so well known, for much interesting information about caterpillar hairs. He has shown me under the microscope that the hairs of the woolly bear caterpillar, that is, the larva of the tiger moth, are all of them coarsely barbed, and indeed this can easily be seen with an ordinary corneal lens, but it is a curious fact that the barbs point, not as one would expect, backwards, so as to facilitate the penetration of the hair, but forwards, towards its point, and would therefore seem to be planned to prevent their penetration.

It has been suggested that the hairs are capable of migration in the tissues of the eye; were the barbs directed so as to point away from the point of the hair, this phenomenon would seem likely, but arranged as they are, it would seem to be almost impossible of occurrence. In the case of the gold-tailed moth, Eltringham's diagrams show the barbs pointing away from the point of the hair, and so it would seem migration in that case might well occur.

It has been suggested that the hairs contain some form of poison, and in confirmation of this it is stated that they are much less irritating after being washed with alcohol, and that the alcoholic washings possess irritating properties, and further, that hairs taken from a dead caterpillar produce much less severe lesions than do those from the living larva. These observations, however, have been disputed, and appear to be lacking in verification. At the same time, it would seem that the severity of the inflammation with the formation of hypopyon, and its long course, extending into months, would strongly suggest that it was not due simply to the presence of a small, inert, foreign substance in the cornea, but that some potent poison was responsible for it.

\title{
FRAME FITTING BY PHOTOGRAPHY
}

\author{
BY \\ ERNEST E. MADDOX \\ BOURNEMOUTH
}

THE corneae and pupils are, as we know, misleading indices for the fitting of frames and especially for bifocals. The only rational criteria are the points on the two corneae which the visual axes traverse, and which the squint camera, details of which I published thirty years ago*, mapped out by what we might call " circumlental photography," that is to say, by surrounding the lens of the camera with a reflecting or brightly illuminated surface so as

* Ocular Muscles-1st edition, p. 333, 2nd edition, p. 209. 
practically to convert the camera into an observer with an ophthalmoscope.

The plan which I worked out at the same time for spectacle centering, was to take a circumlental photograph, of exact life size, and lay upon the finished picture a transparent sheet of celluloid marked with cross lines to enable the measurements required to be studied at leisure. The best-fitting unglazed spectacle or eyeglass frame, chosen out of a considerable stock, was to be first placed upon the patient's face, to be included in the photograph.

It was more particularly for bifocal lenses that I felt the need of greater accuracy, and if trifocals should come into use, the need would be greater still. A much larger proportion of the population would, I venture to believe, tolerate these useful lenses better were adjustment of the reading segments quite correct.

Perhaps more important still is the accurate adjustment of a pair of strong cataract lenses. We all know how often the benefit of a second operation is largely discounted by the difficulty of getting the eyes to work together, and with very strong lenses every millimetre of departure from the visual axes means a good deal.

The squint camera was easily made at the time, for its own purpose, but its adaptation to frame fitting met with insuperable difficulties, even in the hands of a manufacturer of the first water, so the idea lay dormant for many years, till recently I had the good fortune of a request from Mr. Howard, of Messrs. Curry and Paxton, that he might have a try at it, and his ingenious and painstaking mechanical efforts to ensure accurate focusing have been crowned with success. The chief difficulty-that of securing truly life-size photographs with sufficient accuracy-has been quite overcome, and the patient has only to be seated before the visuaximeter*, as it may be called, shown in Fig. 1, for the photograph to be taken in a few seconds. The results are shown in the succeeding figures.

. Fig. 2 shows a white line down the centre of the patient's nose, which $\mathrm{Mr}$. Howard has ingeniously worked in, and the little squares of the scale are in millimetres. The corneal reflections are seen, just as in my squint camera, as little white discs with a black spot, to indicate the visual axis, in the centre of each; this black spot corresponds to the lens of the camera in the midst of its white surround. The displacement of the visual axis from the centre of the cornea, which depends on the angle gamma, can be seen to be about normal, in each eye, in this case, and the visual axes are of equal height, though that of the right is $28.5 \mathrm{~mm}$. from the middle line, and that of the left $31.5 \mathrm{~mm}$. It should be explained that these photographs are taken for a reading distance of $14 \mathrm{in}$. That

\footnotetext{
* In the possible patenting of this instrument by the manufacturers as a recompense for their time and trouble, I have no part.
} 


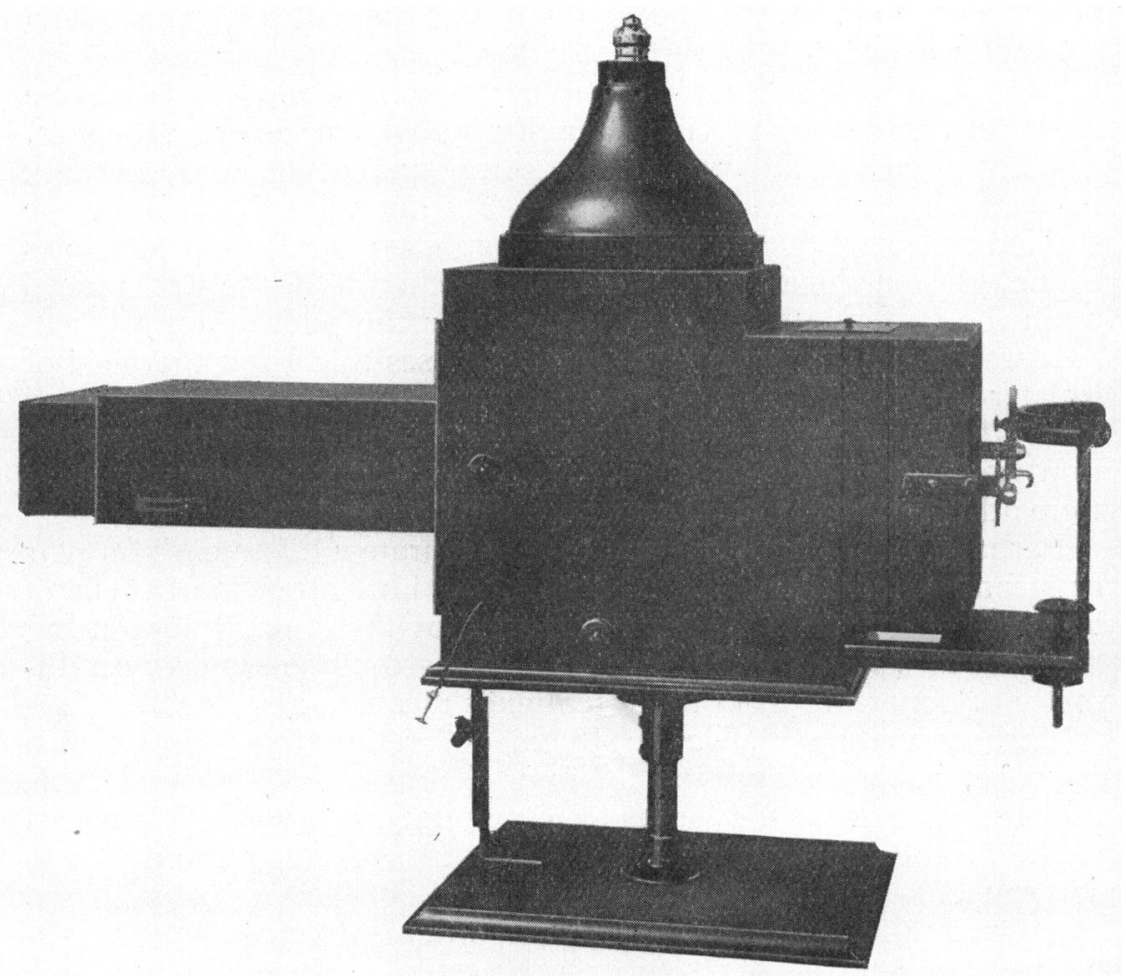

FIG. 1.

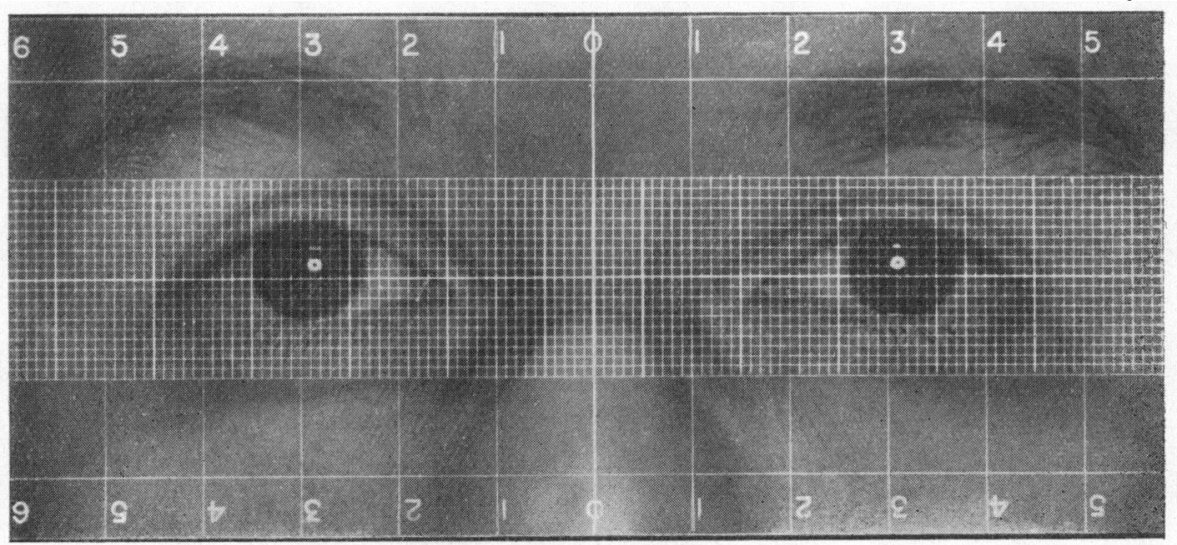

FIG. 2. 
being known, it is a simple matter to read from a table what their separation would be in distant vision.

Fig. 3 illustrates how well the difference in height of the two eyes comes out, though one is only $4 \mathrm{~mm}$. above the other. It must

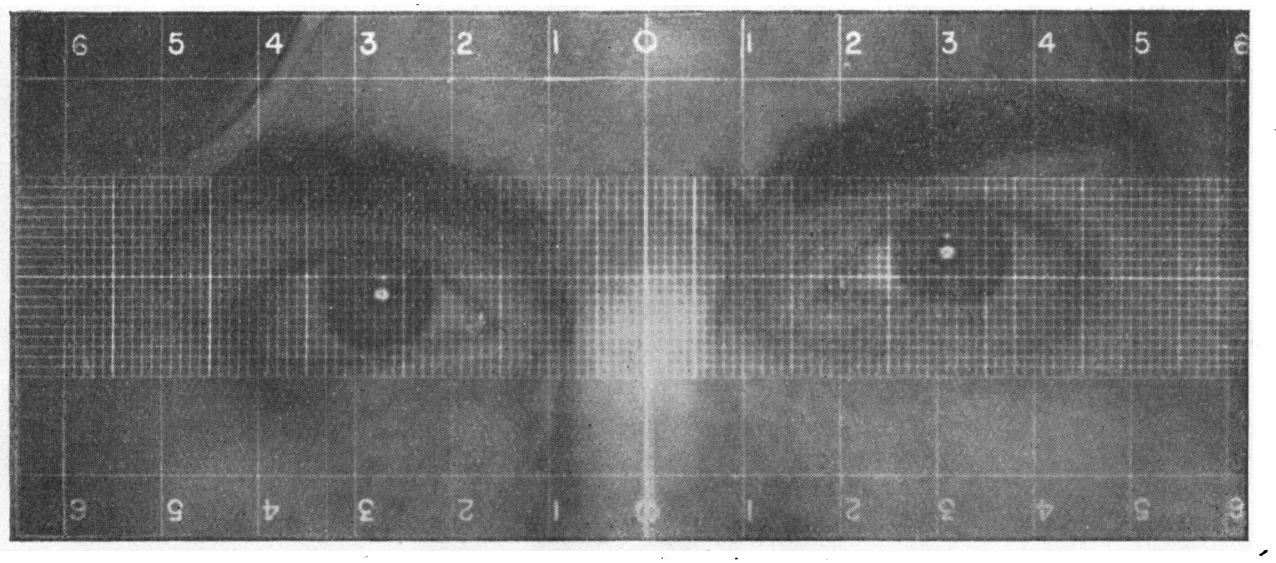

Fig. 3.

at once be evident how much more accurate this method of frame fitting must be than those usually employed.

For bifocals my plan included celluloid templets cut to the shape of all the ordinary kinds of reading segments. These were to be laid over the finished photograph, so that by running a fine pencil round their edge, their most approved position and size could be studied and marked before the photograph is passed on to the workshop.

\section{PSEUDO-GLAUCOMA}

BY

\section{Alexander MacRae}

\section{NEWCASTLE-ON-TYNE}

IN view of Dr. Adalbert Fuchs' interesting paper on this subject in the February number, 1928, the following case, which differs in some features from any of his, is perhaps worth recording.

The patient, C.M., a girl, aged 13 years and 9 months, was found on routine school examination to be blind in her right eye. The Ophthalmic School Medical Officer, Dr. Norman Wren, on looking at the fundus at once recognised the rarity of the condition and asked me to see her with him. 